\title{
The Effects of Reducing the Structural Mass of the Transit Habitat on the Cryogenic Propellant Required for a Human Phobos Mission
}

\begin{abstract}
A technique for rapidly determining the relationship between the pressurized volume, structural mass and the cryogenic propellant required to be delivered to Earth orbit for a Mars Transit Habitat is provided. This technique is based on assumptions for the required delta-V's, the Exploration Upper Stage performance and the historical structural masses for human spacecraft from Mercury Program through the International Space Station. If the Mars Transit Habitat is constructed from aluminum, structural mass estimates based on the habitat pressurized volume are accurate to within 15\%. Other structural material options for the Mars Transit Habitat are also evaluated. The results show that small, achievable reductions in the structural mass of the Transit Habitat can save tens of thousands of pounds of cryogenic propellant that need to be delivered to Earth orbit for a human Phobos Mission.
\end{abstract}

\section{INTRODUCTION}

A notional human Phobos mission is shown in Figure 1. A key component of this mission, the Mars Transit Habitat, would be sent to Mars on a seven to ninemonth trip, could remain in Mars Orbit for approximately 16 months and then return to Earth with an entry vehicle (currently assumed to be the Orion Spacecraft) attached to it. With the Orion Spacecraft and a Mars Insertion Stage docked to the Mars Transit Habitat, a large quantity of cryogenic propellant would be needed to inject this combined stack on a trajectory towards Mars.

The purpose of this paper is to present the relationship between the pressurized volume and structural mass of a notional Mars Transit Habitat and the amount of cryogenic propellant required in Earth Orbit (assumed to be a 3,000 km circular orbit) to deliver the Mars Transit Habitat/Orion Spacecraft combination to Mars Orbit (assumed to be a $500 \mathrm{~km}$ circular orbit). This analysis relies on assumptions for the performance of the Exploration Upper Stage (EUS), the Mars Insertion Stage (MIS), the delta-V's required as well as historical data from human spacecraft derived from JSC-26098, Design Mass Properties II. 
While differences in the performance of the cryogenic propulsion systems chosen and the orbit parameters at both Mars and Earth will affect the results of this study, the overall trend of the sensitivity between the structural mass of the Mars Transit Habitat and the cryogenic propellant required to be delivered to Earth orbit is compelling. The results of this study show that small, achievable decreases in the structural mass of the Mars Transit Habitat can significantly reduce the amount of cryogenic propellant that needs to be delivered to Earth orbit and, therefore, the overall mission cost.

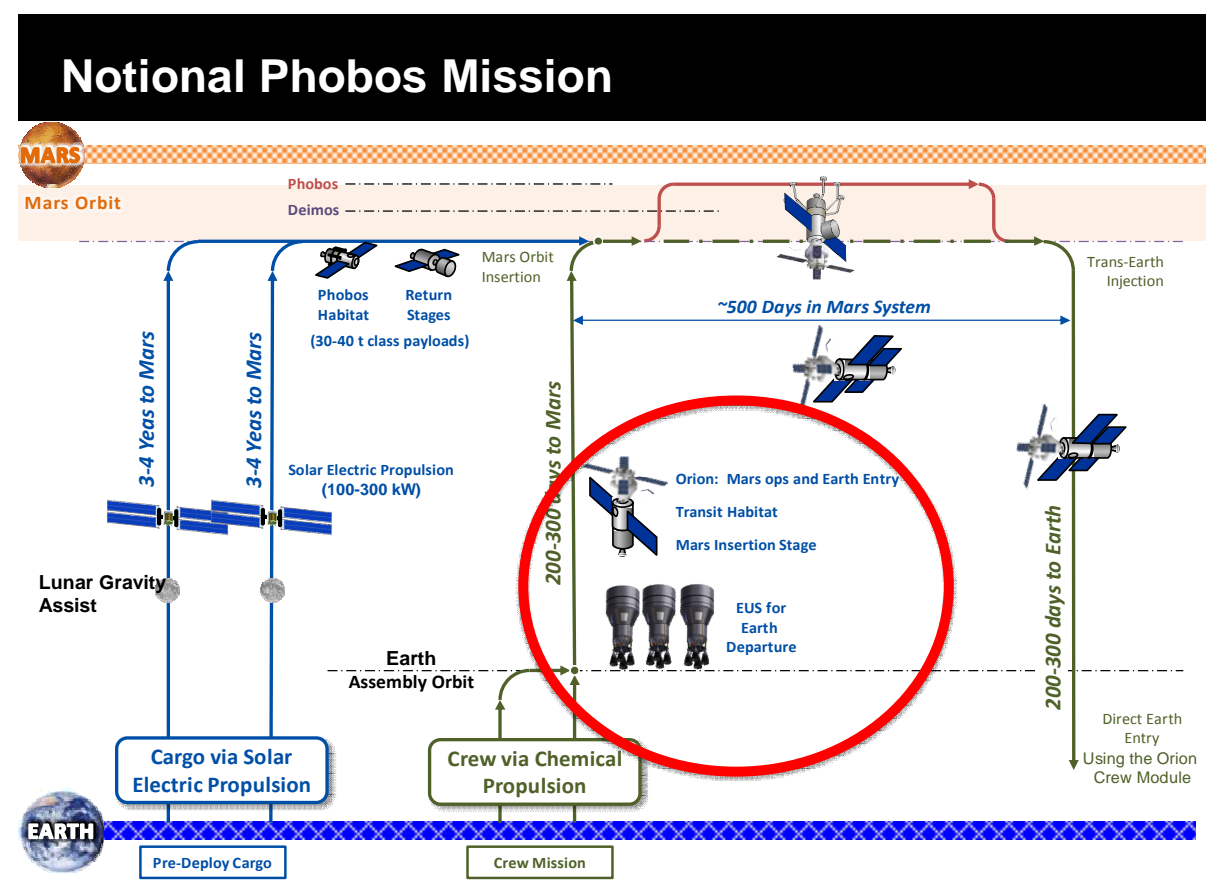

Figure 1 - Notional Phobos Mission

ASSUMPTIONS

In the notional Phobos mission, the Exploration Upper Stage is used to inject the combined Orion Spacecraft / Mars Transit Habitat / Mars Insertion Stage on a trajectory towards Mars. Although the EUS is still under development, the following assumptions are made regarding its performance:

- The EUS can carry a usable cryogenic $\mathrm{L}_{\mathrm{H} 2} / \mathrm{L}_{\mathrm{O} 2}$ propellant load of $106,569 \mathrm{~kg}$. $(234,452 \mathrm{lbs})$

- The EUS inert mass is $14,000 \mathrm{~kg}$. $(30,800 \mathrm{lbs})$

- The $I_{s p}$ for the EUS is $462 \mathrm{~s}$.

- The inert mass fraction is 0.111 . 
Assumptions made regarding the Mars Insertion Stage (MIS) are:

- A cryogenic $\mathrm{L}_{\mathrm{H} 2} / \mathrm{LO}_{\mathrm{O} 2}$ propulsion system with $\mathrm{I}_{\mathrm{sp}}$ of $420 \mathrm{~s}$

- An inert mass fraction of 0.15 .

The Orion Spacecraft mass is assumed to be $25,000 \mathrm{~kg}$. It is also assumed that the Orion Spacecraft's propulsion system is not used during either the Trans-Mars Injection burn or the Mars Orbit Insertion burn.

It is also assumed that the propellant load that is delivered to Earth orbit is usable propellant after both cryogenic propellant boiloff and propellant ullage are considered.

\section{Performance analysis for one EUS cryogenic propellant load delivered to Earth Orbit}

The first case analyzed will be the delivery of one EUS cryogenic propellant load to Earth orbit. This study does not specify how the cryogenic propellant load is delivered, it merely uses the EUS propellant load as a convenient number since the EUS is planned hardware that supports deep space human exploration.

The relationship between the mass of cryogenic propellant delivered (MPROP) for a

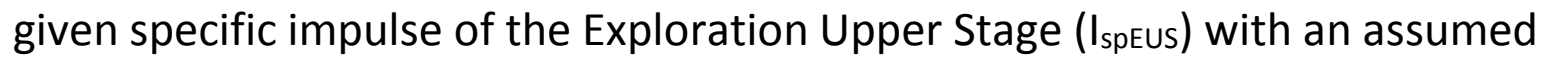
Inert Mass Fraction of the EUS ( $f_{\text {inerteus}}$ ) and for the delta- $\mathrm{V}(\Delta \mathrm{V})$ required for a Trans-Mars Injection burn as a function of the payload mass (MPAY) is given by:

$$
M_{\text {PROP }}=\frac{M_{\text {PAY }}\left(e^{(\Delta V / g \text { IspEUS })}-1\right)\left(1-f_{\text {inertEUS }}\right)}{1-\left(f_{\text {inertEUS }}\right)\left(e^{(\Delta V / g \mid s p E U S)}\right)}
$$

Assume that $4,200 \mathrm{~m} / \mathrm{s}$ is the required $\Delta \mathrm{V}$ to place the Orion Spacecraft / Mars Transit Habitat / MIS combination on a trans-Mars trajectory and insert all of the known values into Equation (1).

$$
\begin{aligned}
& 106,569=\frac{M_{\text {PAY }}\left(e^{(4200 / 9.81 * 462)}-1\right)(1-0.111)}{1-(0.111)\left(e^{\left(4200 / 9.81^{*} 462\right)}\right)} \\
& 106,569=\frac{M_{\text {PAY }}(2.526-1)(0.8889)}{1-(0.28067)}=\frac{M_{P A Y} 1.3564614}{0.71933}=1.88573 M_{\text {PAY }}
\end{aligned}
$$


MPAY $=56,513 \mathrm{~kg}$ is the amount of mass that can be placed by one EUS cryogenic propellant load on a trans-Mars trajectory with the given assumptions. This mass includes the Orion Spacecraft, the MIS and the Mars Transit Habitat.

To calculate the final mass ( $\mathrm{M}_{\text {final }}$ ) that can be placed in Mars Orbit we use this equation:

$$
M_{\text {final }}=M_{P A Y} * e^{(\Delta V / g l s p M I s)}
$$

Assuming the $\Delta \mathrm{V}$ to achieve Mars Orbit is $2,040 \mathrm{~m} / \mathrm{s}$ :

$$
M_{\text {final }}=56,513 * e^{(-2,040 /(9.81 * 420))}=56,513 * 0.6095=34,444 \mathrm{~kg}
$$

The inert mass of the MIS is calculated:

$$
M_{\text {inertMIS }}=0.15^{*}(56,513-34,444)=3,310 \mathrm{~kg}
$$

So, the mass available for the Transit Habitat/Orion Spacecraft combination is:

$$
\text { M AVAlLAble }=34,444-3,310=31,134 \mathrm{~kg} .
$$

Since the Orion Spacecraft mass is assumed to be $25,000 \mathrm{~kg}$, a single EUS cryogenic propellant load will provide 6,134 kg of mass for the Mars Transit Habitat.

\section{Performance analysis for two EUS cryogenic propellant loads delivered to Earth Orbit}

Using Equation (1) and assuming two cryogenic propellant loads of EUS delivered to Earth orbit gives this equation:

$$
213,183=\frac{M_{\text {PAY }}\left(\mathrm{e}^{\left(4200 / 9.81^{*} 462\right)}-1\right)(1-0.111)}{1-(0.111)\left(\mathrm{e}^{\left(4200 / 9.81^{*} 462\right)}\right)}=1.88573 \mathrm{M}_{\mathrm{PAY}}
$$


$M_{P A Y}=113,027 \mathrm{~kg}$ is the mass that can be placed by two EUS cryogenic propellant loads on a trans-Mars trajectory with the given assumptions. This mass includes the Orion Spacecraft, the MIS and the Mars Transit Habitat.

The final mass ( $\left.M_{\text {final }}\right)$ that can be placed in Mars Orbit is calculated using Equation (2):

$$
M_{\text {final }}=113,027 * \mathrm{e}^{\left(-2040 /\left(9.81^{*} 420\right)\right)}=113,027^{*} 0.6095=68,890 \mathrm{~kg}
$$

The inert mass of the MIS is calculated:

$$
M_{\text {inertMIS }}=0.15 *(113,027-68,890)=6,620 \mathrm{~kg} \text {. }
$$

The mass available for the Mars Transit Habitat/Orion combination is:

$$
M_{\text {AVAILABLE }}=68,890-6,620=62,270 \mathrm{~kg}
$$

Assuming the Orion Spacecraft mass is $25,000 \mathrm{~kg}$, the mass available for the Mars Transit Habitat is $37,270 \mathrm{~kg}$.

\section{Determining the Pressurized Volume and Structural Mass of the Mars Transit Habitat}

Using the data and methods contained in JSC-26098, Design Mass Properties II, the pressurized volume $\left(\mathrm{V}_{\mathrm{PR}}\right)$, system mass ( $\mathrm{M}_{\mathrm{SYS}}$ ) and structural mass (MSTR) can be determined for the Mars Transit Habitat, since we have derived its overall mass and can assume a total transit time and number of crew members.

JSC-26098 is a publically available compilation of masses for NASA spacecraft from Mercury Program through the ISS Program. It was written by a dedicated weights engineer, Mr. William (Buddy) Heineman, Jr. who painstakingly compiled detailed mass breakdowns of NASA spacecraft and developed relationships between their structure and system masses to their pressurized volume and design envelope areas using similar techniques that are used to project weights of aircraft. This document has been and will continue to be an invaluable resource for human 
spacecraft conceptual design because data on actual flown human spacecraft can be researched and projected based on preliminary configuration concepts and top-level mission requirements.

We assume the transit time from Earth orbit to Mars Orbit is 270 days (NDAYs). We also assume that crew complement is 4 ( $\mathrm{N}_{\text {CREW }}$ ) and the gross mass ( $\mathrm{M}_{\text {Thab }}$ ) of the Mars Transit Habitat is lbs 82,255 lbs $(37,270 \mathrm{~kg})$.

Using Figure 2, derived from Example 4 of JSC-26098, we solve Equation (3):

$$
\begin{aligned}
& M_{\text {Thab }}=330.51 *\left(N_{\text {CREW }} * N_{\text {DAYS }} * V_{P R}\right)^{0.3574}(3) \\
& 82,255=330.51 *\left(4 * 270 * V_{P R}\right)^{0.3574} \\
& 248.87=\left(1080 * V_{P R}\right)^{0.3574} \quad \text { Note: }(x y)^{n}=x^{n} y^{n} \\
& 20.50=V_{P R}^{0.3574} \\
& 1.312=0.3574 \log V_{P R} \\
& 3.67=\log V_{P R} \\
& 10^{3.67}=V_{P R}=4,677 f t^{3}
\end{aligned}
$$

This volume is roughly the pressurized volume of the International Space Station U.S. Laboratory Module ("Destiny").

For the case of one EUS cryogenic propellant load where $13,538 \mathrm{lbs}(6,134 \mathrm{~kg})$ of mass are available, a similar calculation shows that $V_{P R}=30 \mathrm{ft}^{3}$. This is less than the pressurized volume of the Mercury capsule $\left(50 \mathrm{ft}^{3}\right)$, so this is insufficient volume for a Mars Transit Habitat.

A third EUS cryogenic propellant load would provide significantly more volume, so the next task is to develop relationships between the cryogenic propellant delivered to Earth Orbit and the structural and system masses of the Mars Transit 
Habitat, using the data and relationships in JSC-26098 for a range of cryogenic propellant mass of $220,000 \mathrm{lbs}(100,000 \mathrm{~kg})$ to $660,000 \mathrm{lbs}(300,000 \mathrm{~kg})$ delivered to Earth orbit.

Also, the mass of the Earth Entry Vehicle (EEV) of 55,175 lbs. (25,000 kg.), assumed to be the Orion Spacecraft in these calculations, has a significant effect on the amount of mass and volume available for the Mars Transit Habitat. This entry vehicle is carried from Earth orbit, to Mars orbit and then back to Earth. So, a second sensitivity study is performed for a range of masses of the EEV of zero (assuming rendezvous with the entry vehicle will occur sometime during the mission as the Transit Habitat nears Earth) up to 25,000 kg.

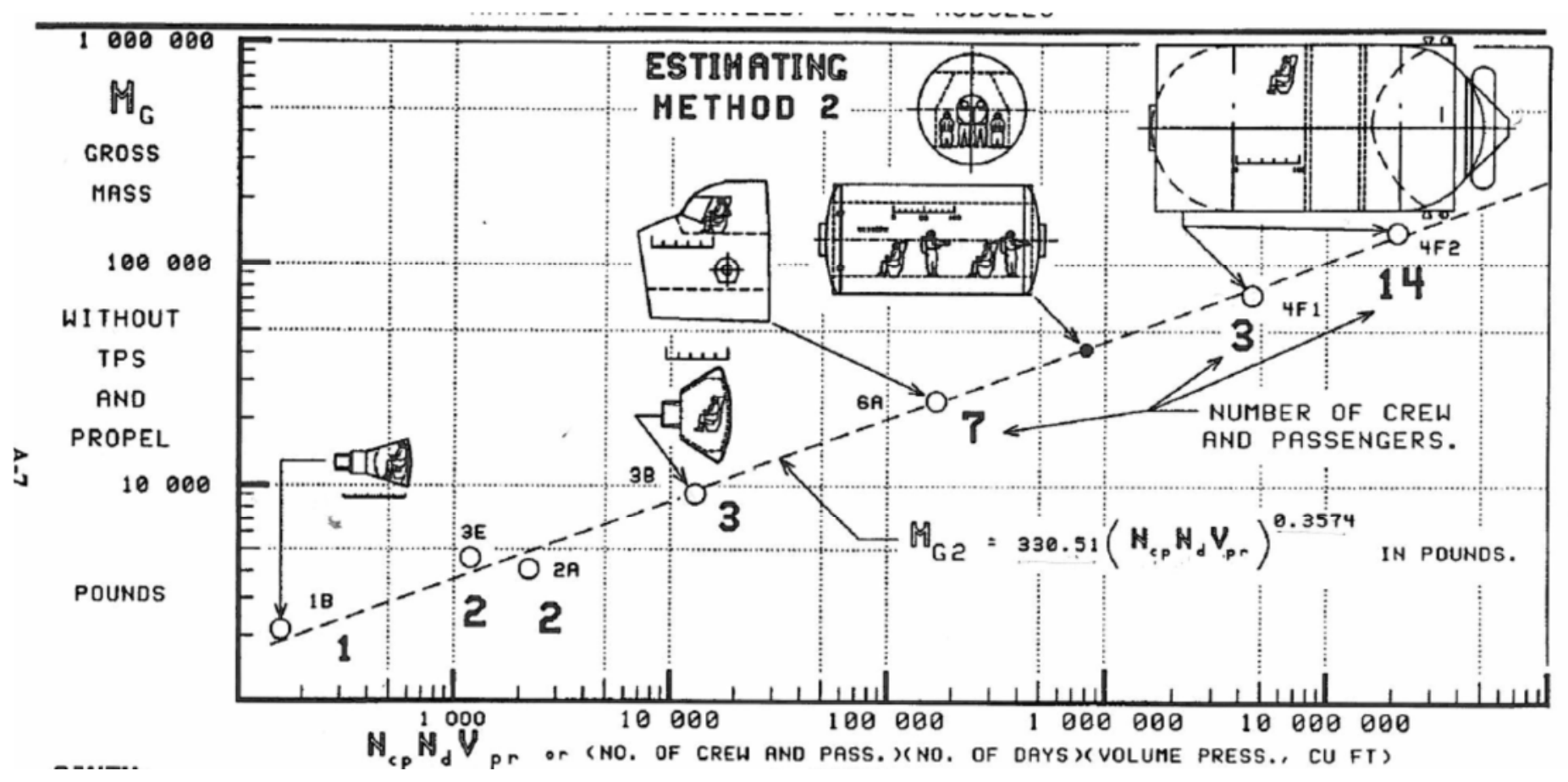

Figure 2 - Total Mass of a Habitable Module as a function of Pressurized Volume, Number of Crew and Mission Duration (Source - JSC-26098) 


\section{Relationship between the Mass of Propellant Delivered to Earth Orbit and the}

\section{Mass of the Transit Habitat}

Based on the previous analysis and assumptions, the cryogenic propellant required for Trans-Mars Injection is related to the payload mass by:

$$
\mathrm{M}_{\mathrm{FUEL}}=1.88573^{*} \mathrm{M}_{\mathrm{PAY}}
$$

The final mass delivered to Mars Orbit is related to the Trans-Mars Injection payload mass by:

$$
0.6095 * M_{\text {PAY }}=M_{\text {final }}
$$

$M_{\text {final }}$ is composed of the mass of the Orion Spacecraft, the mass of the Mars Transit Habitat and the inert mass of the Mars Insertion Stage.

The Inert Mass of the Mars Insertion Stage, MinertMIs, is related to Mpay by:

$$
\begin{gathered}
M_{\text {inertMIS }}=0.15 *\left(M_{\text {PAY }}-M_{\text {final }}\right)=0.15 *\left(M_{\text {PAY }}-0.6095 * M_{\text {PAY }}\right)=0.058575 * M_{\text {PAY }} \\
M_{\text {final }}=0.6095^{*} M_{\text {PAY }}=M_{\text {ORION }}+M_{\text {Thab }}+M_{\text {inertMIS }} \\
M_{\text {final }}=0.6095 * M_{\text {PAY }}=25,000 \mathrm{~kg}+M_{\text {Thab }}+0.058575 * M_{\text {PAY }} \\
M_{\text {Thab }}=0.6095 * M_{\text {PAY }}-0.058575 * M_{\text {PAY }}-25,000 \\
M_{\text {Thab }}=0.551 * M_{\text {PAY }}-25,000
\end{gathered}
$$

Substituting Equation (4) for Mpay gives:

$$
M_{\text {Thab }}=0.2922 * M_{\text {FUEL }}-25,000
$$

Here $\mathrm{M}_{\text {Thab }}$ is the $\underline{\text { total }}$ mass of the Mars Transit Habitat including structures and systems. 
For the given assumptions, Equation (5) relates the mass of cryogenic propellant required in Earth orbit to the total mass of the Mars Transit Habitat. Equation (5) shows that a certain minimum amount of cryogenic propellant is required in Earth orbit for a Mars Transit Habitat of any practical mass to be sent on a Trans-Mars trajectory.

\section{Relationship Between the Mass and the Pressurized Volume of the Mars Transit Habitat}

We now use Equation (3) in order to develop a relationship between the mass of the Mars Transit Habitat and the pressurized volume of the Mars Transit Habitat.

$$
\begin{gathered}
M_{\text {Thab }}=330.51 *\left(N_{\text {CREW }} * N_{D A Y S} * V_{P R}\right)^{0.3574} \\
M_{\text {Thab }}=330.51 *\left(4 * 270 * V_{P R}\right)^{0.3574} \\
M_{T H A B}=4011.72 * V_{P R}^{0.3574} \\
2.49 \times 10^{-4} M_{T H A B}=V_{P R}^{0.3574} \\
\log \left(2.49 \times 10^{-4} M_{T H A B}\right)=0.3574 \log V_{P R} \\
10^{\left(\log \left(2.49 \times 10^{\wedge-4} * M_{T H A B}\right) / 0.3574\right)}=V_{P R} \quad(6)
\end{gathered}
$$

Equation (6) provides the relationship between the mass of the Mars Transit Habitat and the pressurized volume of the Mars Transit Habitat. There is a certain minimum mass of a Mars Transit Habitat that is required to provide a useful amount of pressurized volume. One of the key components to habitability of a long-duration, crewed vehicle is the amount of the pressurized volume. So, using pressurized volume as an independent variable and relating it to key mission parameters such as the Mars Transit Habitat structural mass and propellant delivered to Earth orbit can provide significant insights into the feasibility of a human Phobos mission. 
Figure 3 is a relationship from JSC-26098 that relates the historical masses of the habitable volumes of various human spacecraft to their structure and system masses. A curve fit was performed of the line marked "STRUCTURE" in Figure 3 to determine the equation of the line that relates pressurized volume to habitable structure mass.

This curve-fit produced the equation:

$$
M_{S T R}=26 *\left(V_{P R}{ }^{0.721}\right)
$$

which should predict the habitable structure mass within $+/-15 \%$.

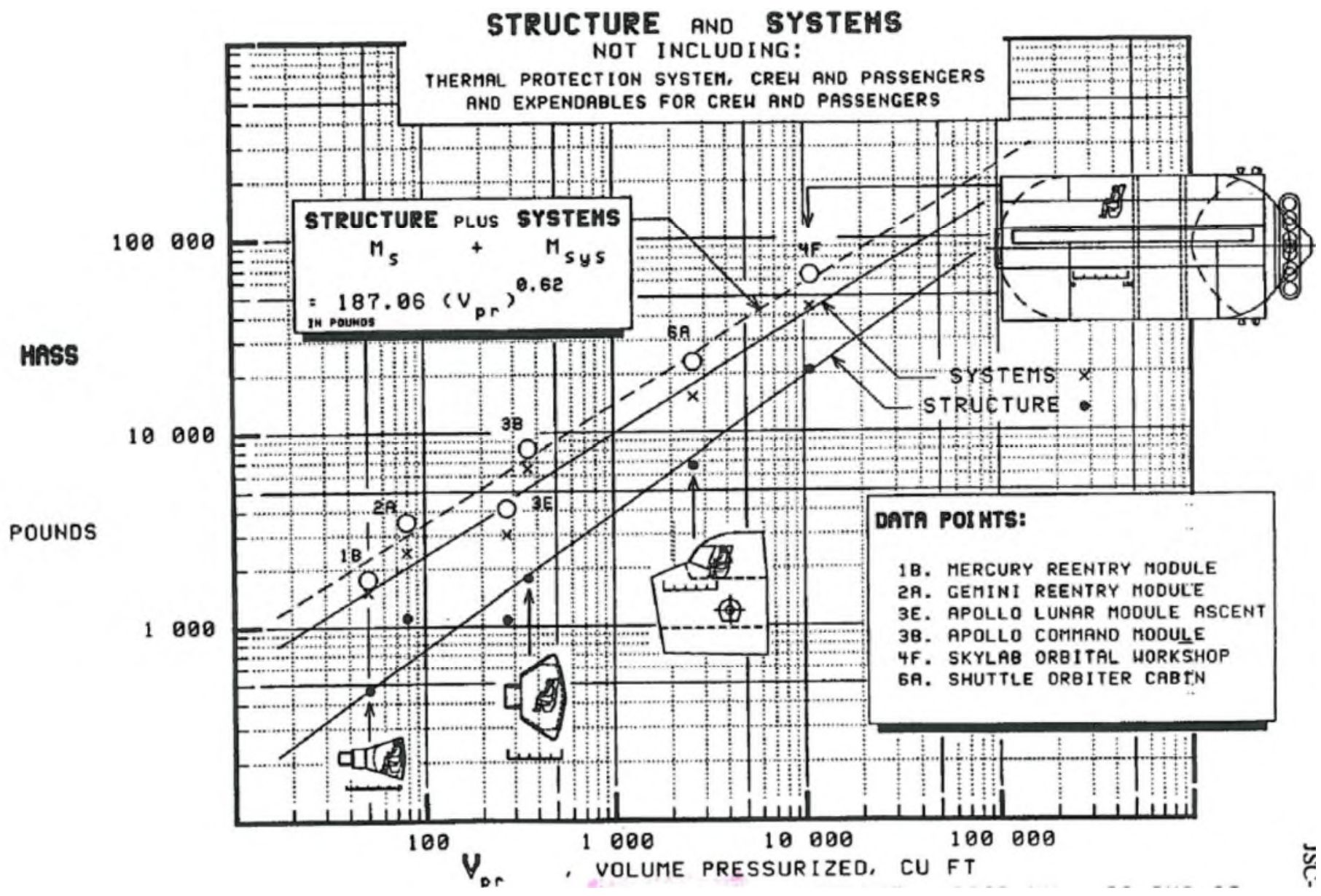

Figure 3 - Habitable Element Structure and System Mass vs. Pressurized Volume 


\section{Presentation of Results}

Equations (1) - (7) and Figures (1) and (2) can now be used to calculate relationships between $\mathrm{M}_{\mathrm{FUEL}}, \mathrm{M}_{\mathrm{PAY}}, \mathrm{V}_{\mathrm{PR}}$ and $\mathrm{M}_{\mathrm{STR}}$. Historical data points are shown on each curves to relate actual human spacecraft masses and volumes to the mass and pressurized volume of a Mars Transit Habitat.

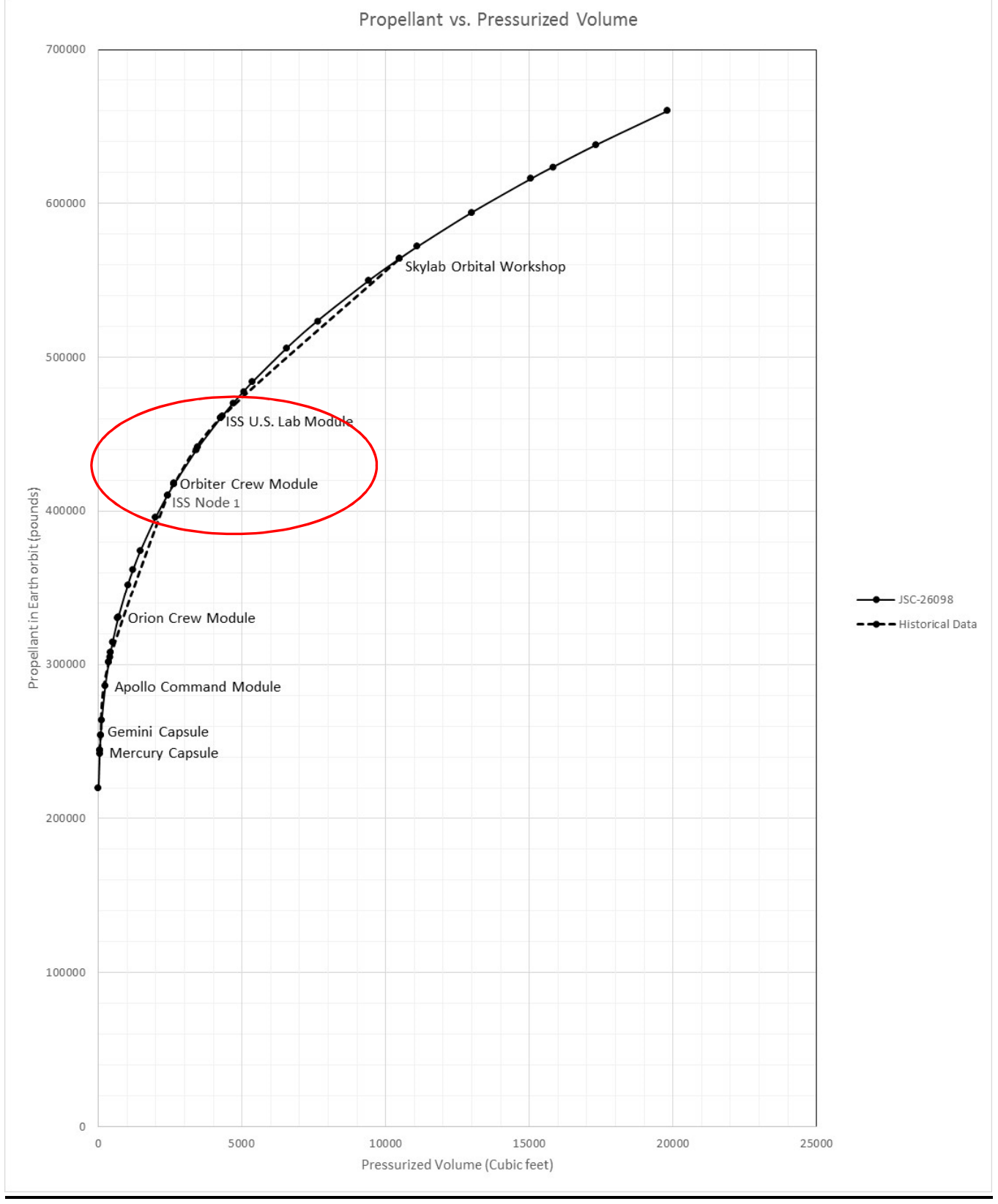

Figure 4-Mars Transit Habitat Pressurized Volume vs. Cryogenic Propellant Delivered to Earth Orbit 
Figure 4 relates the pressurized volume of the Mars Transit Habitat to the cryogenic propellant delivered to Earth orbit. Two curves are presented. The solid curve shows a curve fit of predicted pressurized volumes using the methods in JSC-26098. The dashed curve is a plot of historical pressurized volumes of actual human spacecraft from Mercury through ISS.

The historical data points show examples of the pressurized volume sizes for various human spacecraft. Since we expect a considerable volume would be needed for four crewmembers to support all of the activities required for a 270day Mars transit, the volumes which range from roughly the size of the ISS Node 1 to the ISS U.S. Lab are highlighted in a red circle.

The important conclusion from this curve lies roughly in the region between the ISS Node 1 and the U.S. Lab module pressurized volumes. Depending on the volume required for habitability for 4 crew during the 270-day Mars transit, the amount of cryogenic propellant required in Earth orbit to inject a volume of that size on a trans-Mars trajectory could vary from between $410,000 \mathrm{lbs}$ and 460,000 lbs.

The areas outside the red oval provide either too little volume for a feasible Mars Transit Habitat, or may be too large a volume to be sent on a mission without advancement in structures technology (such as an inflatable habitat), or a prohibitive amount of cryogenic propellant required in Earth Orbit.

This is a significant difference in the amount of cryogenic propellant required passed on the pressurized volume of the Mars Transit Habitat when considering the tankage, the launch vehicle lift capability and the systems required to maintain that amount of cryogenic propellant in orbit during assembly of the Mars Transit Habitat configuration. It also quantifies the relationship between pressurized volume and the cryogenic propellant required for a Mars Transit Habitat.

Figure 5 relates the structural mass of the Mars Transit Habitat to the cryogenic propellant required in Earth orbit. This is an important chart because the question that is asked is, "how does saving structural mass on the habitat relate to the 
mass of cryogenic propellant required and the overall mission mass?" Whether this weight reduction is achieved by reducing the pressurized volume, optimizing the structure or using different materials doesn't make a difference. The overall effect of the structural mass on the total mission mass can be significant.

The solid curve in Figure 5 shows a relationship between structural mass and the cryogenic propellant required in Earth orbit based on the methods in JSC-26098. The dashed curve is a plot of historical data for structural masses of human spacecraft. The apparent discontinuity in the historical data reflects the different densities between the ISS Node 1 and the Orbiter Crew Module. The ISS Node 1 acted as the structural hub of the entire space station and had a much thicker primary structure and extensive internal secondary structure to route utilities from the truss to the other ISS modules.

Again, the area of interest for Figure 5 lies roughly in the region between the ISS Node 1 and the U.S. Lab module structural masses. Within the range of 7,000 lbs to $11,000 \mathrm{lbs}$ of structural mass, the cryogenic propellant required in Earth orbit could vary from between $410,000 \mathrm{lbs}$ and $460,000 \mathrm{lbs}$ (approximately 12.5 to 1 ). 


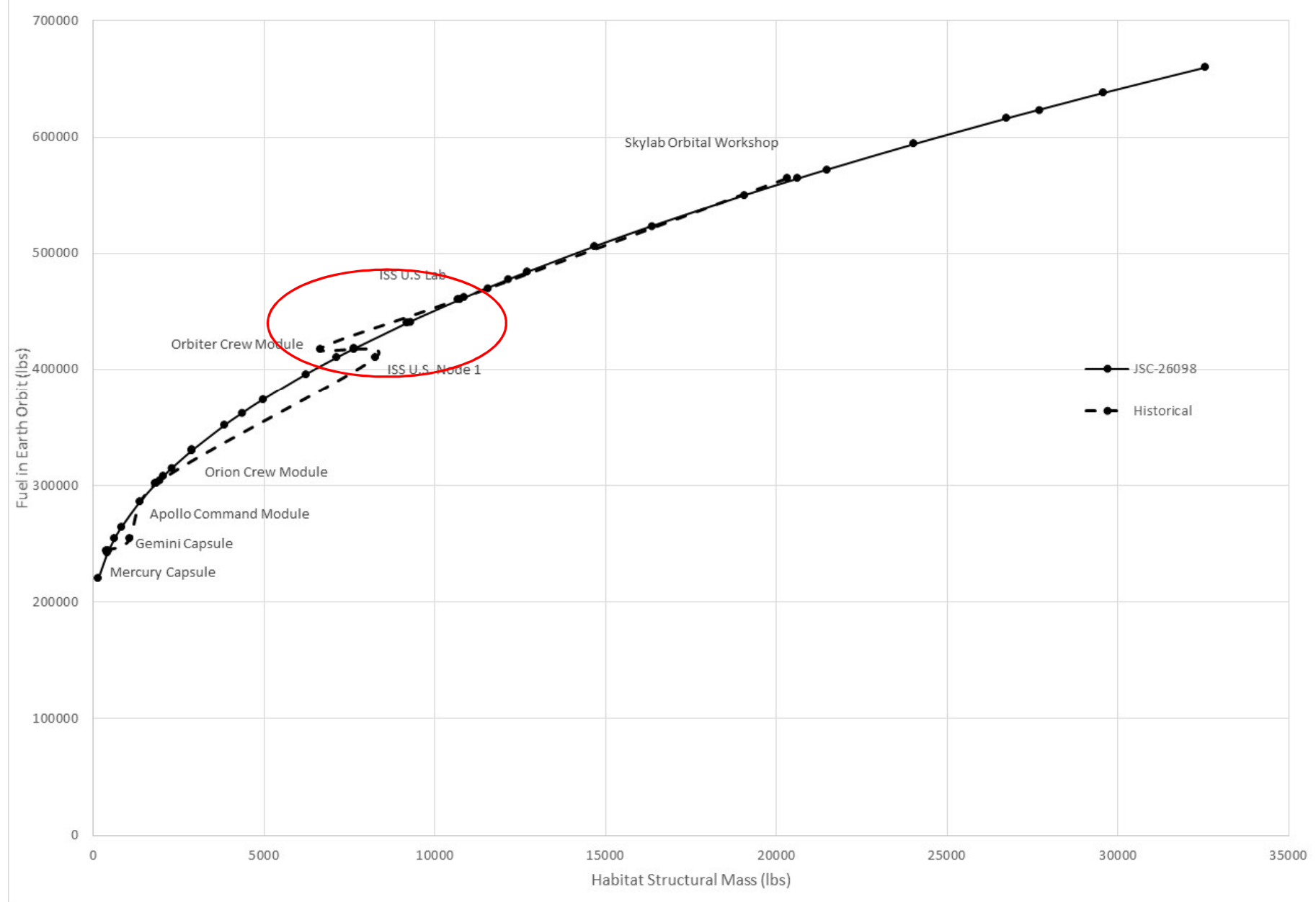

Figure 5 - Payload Structure Mass vs. Cryogenic Propellant Required in Earth Orbit

The usable cryogenic propellant load of two EUS vehicles is approximately $470,000 \mathrm{lbs}$. In the notional Phobos mission architecture, the EUS is used for the Trans-Mars injection burn. Including ullage and boiloff allowances for the cryogenic propellant, reducing the structural mass of the Mars Transit Habitat may be one of the major discriminators that enable that portion of the mission to be performed with two EUS vehicles instead of three. This would be a significant cost savings for an additional launch vehicle as well as in reducing on-orbit 
assembly operations and stay time that should be traded against the investment needed to optimize the Mars Transit Habitat structural mass.

Another important result that is derived in Figure 6 is the total payload capability required for the Mars Transit Habitat / Orion Spacecraft / Mars Insertion Stage combination as a function of Mars Transit Habitat pressurized volume for a 4crew, 270-day mission. Again, the solid curve represents methods from JSC-26098 while the dashed curve overlays historical data from human spacecraft.

Figure 6 shows that a certain minimum payload capacity is needed to provide a minimum useful habitable volume for the Mars Transit Habitat. (For this study, the habitable volume inside the Orion Spacecraft is not accounted for. If Orion is considered part of the Mars Transit Habit Volume, this would reduce the pressurized volume, structural mass, cryogenic propellant required and payload capability required for the mission.)

The area of interest, once again, is roughly between the Node 1 and ISS U.S. Lab habitable volumes. For these volumes, the payload capability needed is between $217,000 \mathrm{lbs}$ and $244,000 \mathrm{lbs}$. This relationship can help determine the payload capacity required for the launch vehicle or vehicles to deliver this combination to Earth Orbit. Currently the 70t, 110t and 130t variants of the Space Launch System (SLS) are envisioned. Judicious management of mass may permit the Mars Transit Habitat / Orion Spacecraft / Mars Insertion Stage combination to be launched into an orbit around the Earth by a single 130t SLS vehicle. 


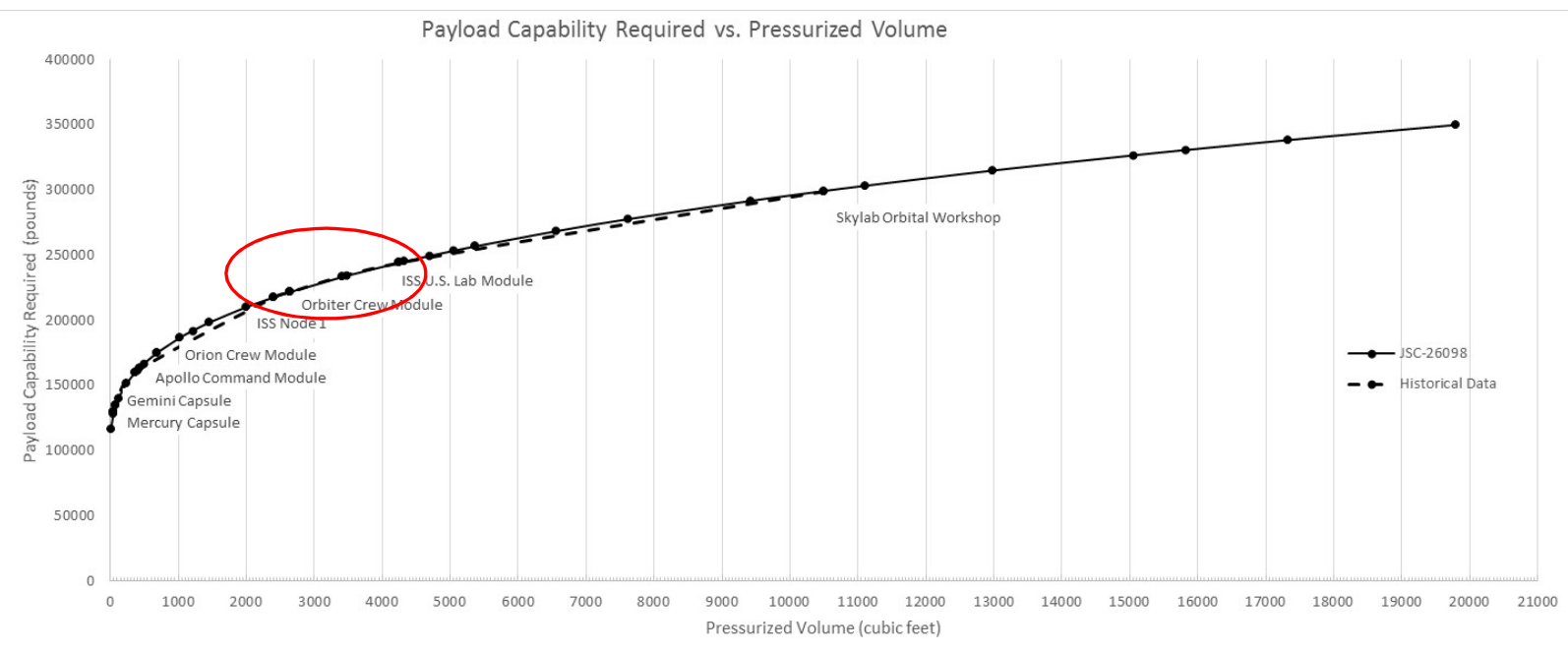

Figure 6-Payload Capability Required vs. Pressurized Volume

\section{Sensitivity Studies}

It was stated previously that the structural mass estimates developed using the methods of JSC-26098 are accurate to within $+/-15 \%$. With this range, the effect on the calculated cryogenic propellant masses required for delivery of the Mars Transit Habitat for modules with pressurized volumes in the range of the ISS Node 1 to the U.S. Lab is approximately $4 \%$, or about $7,000 \mathrm{~kg}(15,400 \mathrm{lbs})$ to $9,000 \mathrm{~kg}$ $(19,800 \mathrm{lbs})$. This amount of fuel could be added to the cryogenic propellant mass ranges stated previously.

Figure 7 shows the relationship between the cryogenic propellant mass required in Earth orbit vs. the Mars Transit Habitat pressurized volume for a range of EEV masses. For a 20,000 kg EEV (a reduction of 5,000 kg from the current Orion mass), there can be between a $50 \%$ and $60 \%$ increase in the pressurized volume of the Mars Transit Habitat for modules with pressurized volumes in the range of the ISS Node 1 to the U.S. Lab (highlighted by the red box). This is because more mass can be allocated to the Mars Transit Habitat since 5,000 kg of EEV mass will not have to be transported to Mars and back. This is an extremely significant result. This shows that small reductions in the EEV mass can result in significant payback in terms of the Mars Transit Habitat available mass and volume. Figure 7 also shows curves for EEV masses of both 15,000 kg and 10,000 kg. A case where 
the EEV is not brought to and from Mars is included as a lower bound for the analysis.

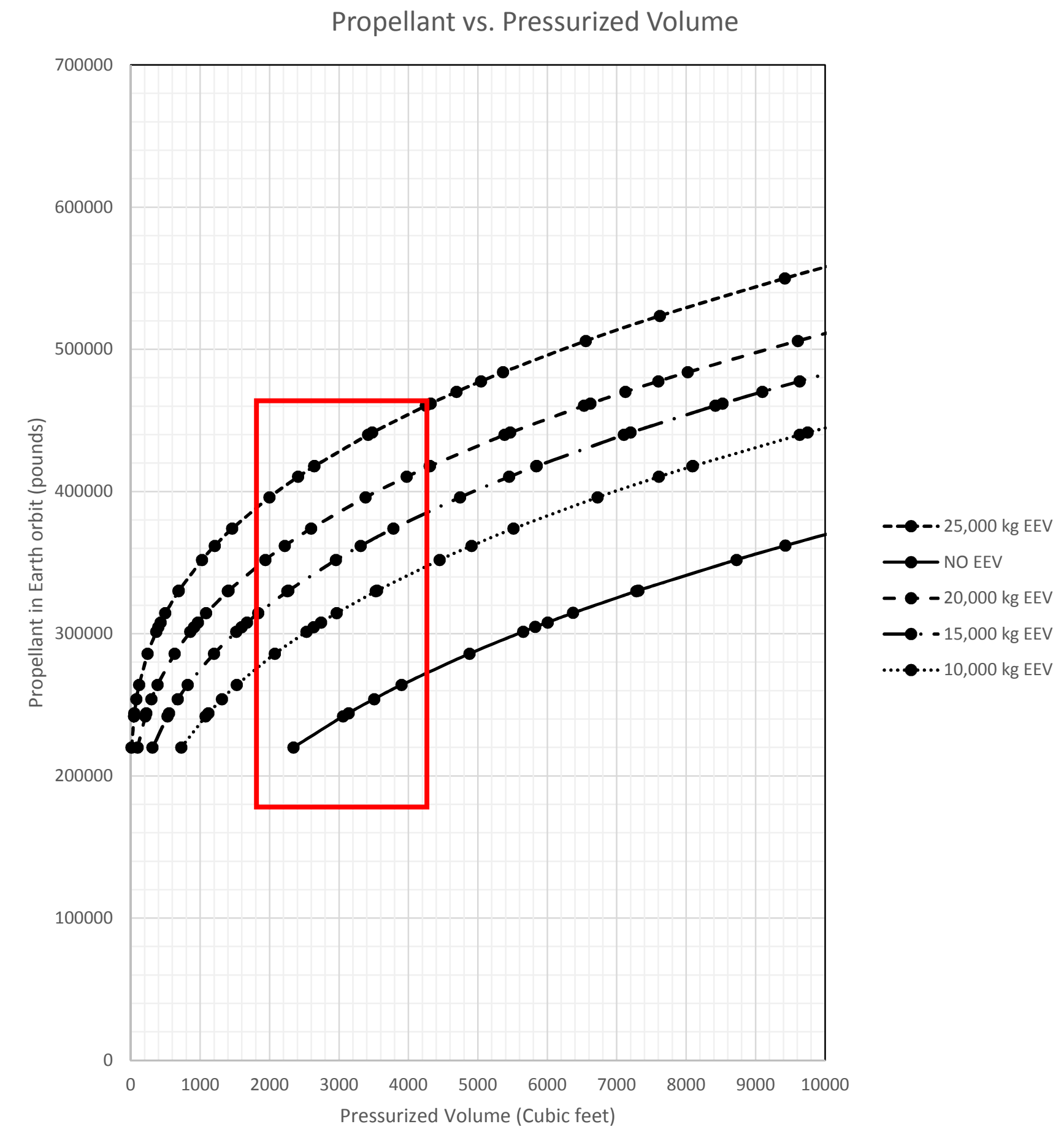

Figure 7 - Cryogenic Propellant Required in Earth Orbit vs. Mars Transit Habitat Pressurized Volume for a Range of EEV masses 
Finally, a discussion of alternate structural materials for habitable volume construction besides aluminum is worth pursuing. All of the historic human spacecraft habitable module data and JSC-26098 methods are based on aluminum as the structural material. An assessment of potential alternate structural materials and the benefits they might provide follows.

Figure 8 shows a limited comparison of the state-of-the art in inflatable structures vs. the historical human habitable aluminum structures as a relationship of structural mass vs. pressurized volume. Only two data points for inflatable structures are available, the TransHab developed at JSC in the late 1990's and the Bigelow Expandable Activities Module (BEAM).

While Figure 8 seems to indicate there is no advantage for using an inflatable structures from a mass vs. volume standpoint, it must be remembered that the inflatable structures technology at this time uses high factors of safety on pressure (on the order of 4.0 vs 2.0 for metallic habitable structures) because considerations like creep rupture life of the fabric restraint layer is still difficult to quantify. It can be expected as inflatable structures mature to the point that comparable factors of safety to aluminum can be used, significant mass advantages as a function of pressurized volume should be achieved.

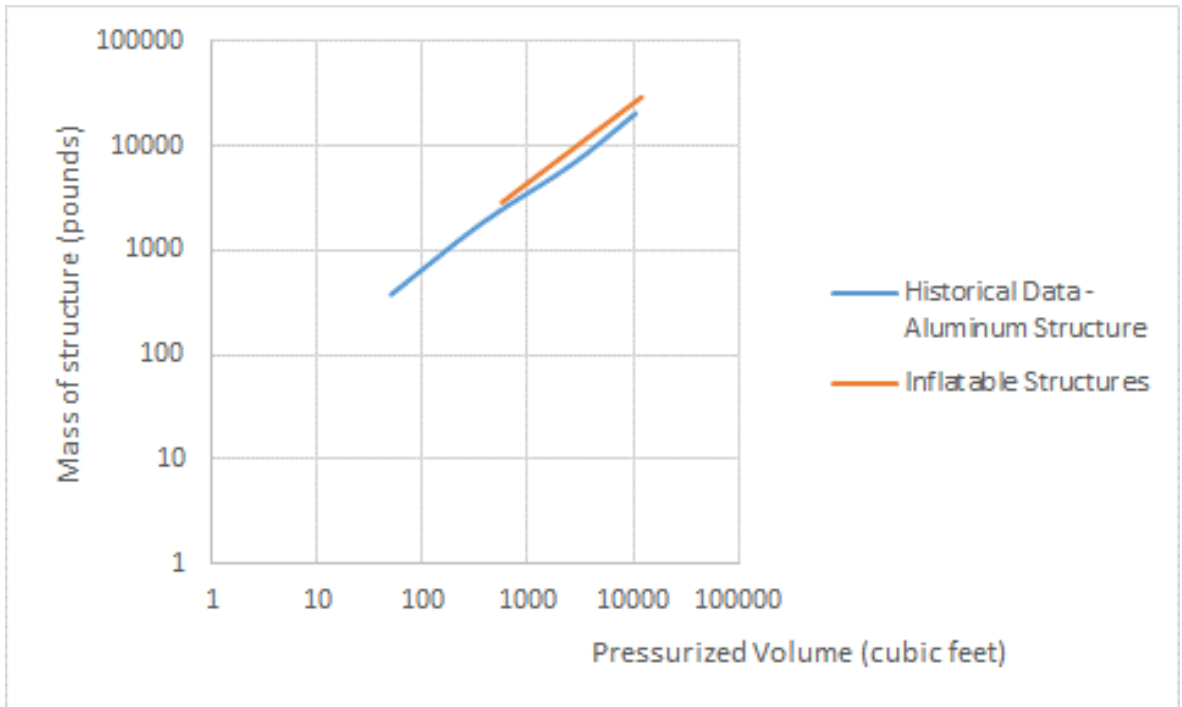

Figure 8 - Inflatable and Aluminum Structure Masses vs. Pressurized Volume 
A fully composite habitable module has yet to be flown in human spaceflight applications as of this writing. Therefore, it is difficult to quantify the weight advantages that could be achieved. Composite habitable modules might be used to reduce manufacturing costs when compared to an aluminum module that must be welded together from curved skin panels, ring forgings and longitudinal stringers.

The most reasonable approach when discussing composite structures might be a percentage weight reduction when compared to aluminum structures. If this percentage is between $10 \%-15 \%$ of the module pressure wall, the relationships that have been presented in this paper show that significant mass reductions in the cryogenic propellant required to be delivered to Earth orbit and the payload capability required as a function of pressurized volume can be achieved.

\section{Conclusions}

This paper relates the structural masses and pressurized volumes of actual human spacecraft to the payload capability and cryogenic propellant delivery requirements of a Mars Transit Habitat for a notional Phobos mission. The methods presented herein are generic and can be generalized for different assumptions than the ones used for this study where results are presented.

Even if different assumptions are used for inert mass fractions, engine $I_{s p}$ or entry vehicle spacecraft mass, this study clearly shows the relationships between Mars Transit Habitat pressurized volume and structural mass and the cryogenic propellant required in Earth Orbit to place the required elements on a Trans-Mars trajectory. It also shows the significant benefits for reducing the cryogenic propellant required to be delivered to Earth orbit that can be achieved by reducing the Mars Transit Habitat structural mass (approximately 12.5 to 1). Reductions in the EEV mass can also be used to reduce the overall system mass, reduce the overall mission cost or provide more capability for Mars Transit Habitat, payload hardware, logistics or scientific experiments.

With the assumptions for $\Delta \mathrm{V}, \mathrm{I}_{\mathrm{sp}}$, EUS propellant capacity, Orion mass and propulsion stage mass fraction, the results show that reductions in Mars Transit 
Habitat structural mass have a direct bearing on the number of launch vehicles required to deliver both the propellant required to perform the Trans-Mars Injection burn and the Mars Transit Habitat / Orion Spacecraft / Mars Insertion Stage combination. A trade between the effort required to attain reasonable reductions in the Mars Habitat Structural Mass and the number of launch vehicles required is likely to conclude that investing in structural mass reductions will provide a significant payback.

It is hoped that this paper and the results herein can be used as a tool for rapid sizing of a Mars Transit Habitation element and in developing conceptual designs for Mars mission architectures. 


\section{APPENDIX}

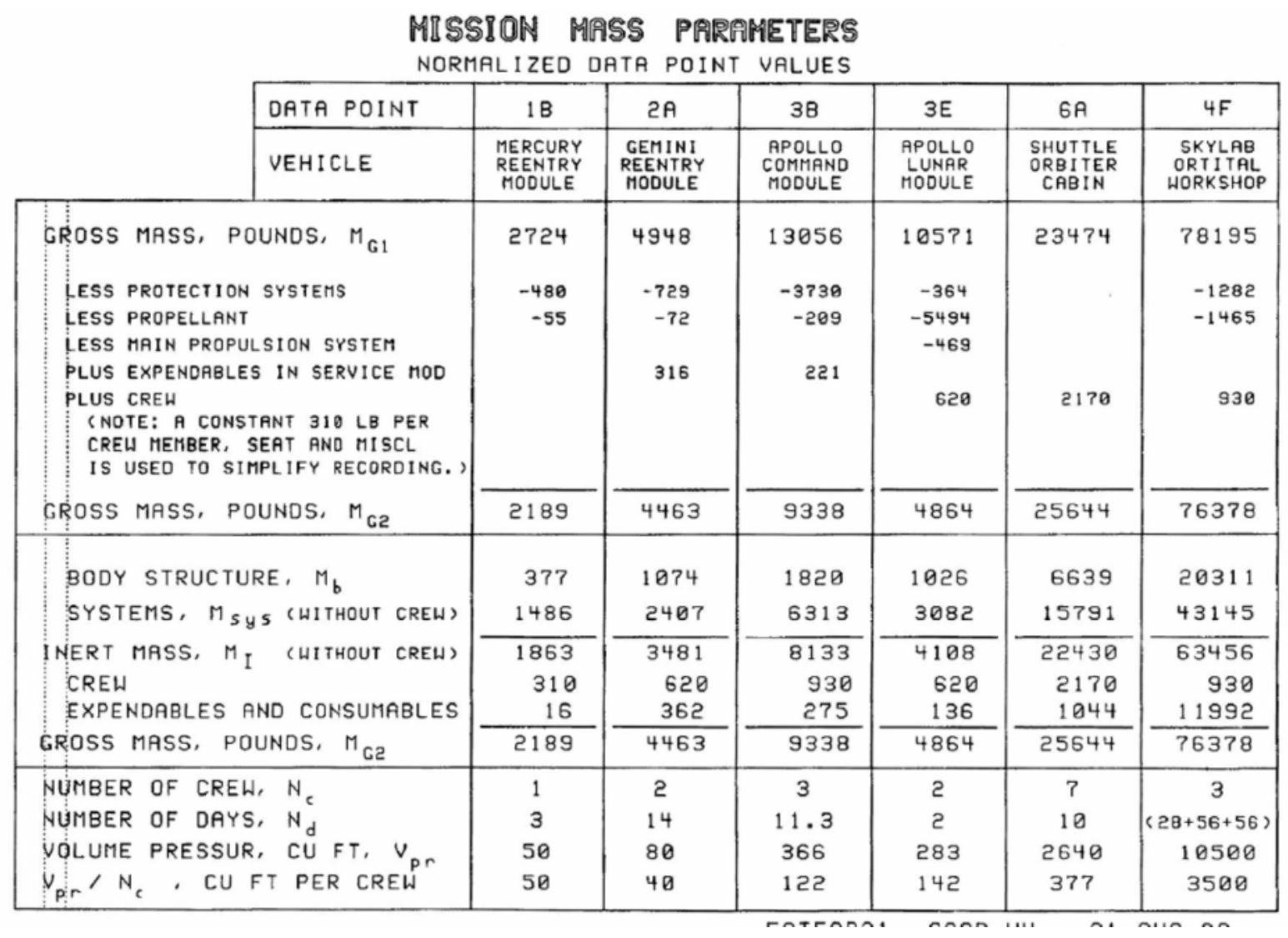

TABLE A-1: Historical Mass Properties for Human Spacecraft from JSC-26098 